\title{
Effect of differentiating agents (all-trans retinoic acid and phorbol 12-myristate 13-acetate) on drug sensitivity of HL60 and NB4 cells in vitro
}

\author{
Ewa Jasek, Jadwiga Mirecka, Jan A. Litwin \\ Department of Histology, Jagiellonian University Medical College, Krakow, Poland
}

\begin{abstract}
In vitro studies have shown that human myeloid leukemia cell lines: HL60 and NB4 can be stimulated to differentiation by various agents, for example, all-trans retinoic acid (ATRA) and phorbol 12-myristate 13-acetate (PMA). The purpose of this study was to investigate whether differentiation of HL60 and NB4 leukemia cell lines induced by ATRA and PMA alters their drug sensitivity. The differentiation along the neutrophil lineage (upon stimulation with ATRA) and along the monocyte/macrophage lineage (upon stimulation with PMA) was proved by decreased proliferative potential of cells, changes in their morphology, increased ability for NBT reduction and increased expression of CD11b and CD14 cell surface markers. The effect of drugs: cytosine arabinoside, daunorubicin, mitoxantrone and etoposide was examined by Alamar Blue test (proliferation and survival rates), as well as by evaluation of cell smears stained with Hoechst 33342 (apoptotic index). Differentiation resulted in the change of drug sensitivity in both cell lines: the differentiation along the neutrophil pathway (after stimulation with ATRA) increased sensitivity to cytosine arabinoside and mitoxantrone but decreased sensitivity to etoposide; the differentiation along the monocyte/macrophage pathway (induced by PMA) resulted in the decreased sensitivity of both cell lines to all drugs tested. In conclusion, we have shown that ATRA- and PMA-mediated differentiation of HL60 and NB4 cell lines results in the changes of their drug sensitivity. Our data may provide a contribution to a strategy aimed at a rational combination of differentiating agents and conventional anticancer drugs.
\end{abstract}

Key words: Leukemia - ATRA - PMA - Differentiation - Apoptosis

\section{Introduction}

A number of human myeloid leukemia cell lines arrested at different stages of differentiation have been established over the years and they provide good models for studies of acute myeloid leukemia (AML). Further differentiation of these lines can be induced by various agents, for example, all-trans retinoic acid (ATRA) and phorbol 12-myristate 13-acetate (PMA) [1-5].

ATRA, an isoform of retinoic acid (the active metabolite of vitamin A) seems to play an important role in the control of hematopoiesis and regulates cell growth and differentiation [6-8]. PMA is a stable analogue of 2,3-diacyloglicerol that activates isoform of protein kinase C (PKC) [9,10]. In vitro studies have shown that human leukemia cell lines: HL60

Correspondence: E. Jasek, Dept. Histology, Jagiellonian University Medical College, Kopernika 7, 31-034, Kraków, Poland; tel./fax: (+4812) 4227027,

e-mail: ewajasek@poczta.onet.pl (myeloblastic) and NB4 (promyelocytic) can be induced to enter diferentiation along the neutrophil lineage upon stimulation with ATRA or along the monocyte lineage after PMA treatment, resulting in morphological and functional changes accompanied by a loss of proliferative capacity. Moreover, differentiation therapy with ATRA has been proved to be very effective and has now become an established method of treatment in acute promyelocytic leukemia (APL) [11$15]$.

It is not clear whether differentiation agents have an effect on leukemia cell sensitivity to chemotherapeutic drugs. Common anticancer drugs can stop cell proliferation and/or induce cell death: apoptosis or necrosis, but a major limitation of such conventional therapy is drug resistance of leukemic cells. On the one hand, differentiated cells which are arrested in G0 phase may be less sensitive to anticancer agents because cytotoxic effect on tumor cells is stronger when cells are in $\mathrm{S}$ phase of the cell cycle. On the other hand, induction of differentiation may provide changes in pro- and antiapoptotic gene expression, facilitating apoptosis in 
leukemic cells: ATRA downregulates bcl-2 expression and increases AML sensitivity to cytosine arabinoside (Ara-C) induced apoptosis in vitro $[13,16]$.

The aim of this study was to examine the potential cytostatic and cytotoxic effect of drugs conventionaly used in AML treatment (Ara-C, daunorubicin, mitoxantrone and etoposide) on HL60 and NB4 cell lines, following incubation with ATRA or PMA.

\section{Materials and methods}

Drugs. ATRA (Sigma) and PMA (Sigma) were dissolved in DMSO to get stock solutions of $1 \mathrm{mM}$ and $1.6 \mathrm{mM}$, respectively; these were stored at $-20^{\circ} \mathrm{C}$ until required. The final concentration of DMSO in cultures did not exceed $0.1 \% \mathrm{v} / \mathrm{v}$. All cytotoxic drugs (Ara-C, daunorubicin, mitoxantrone and etoposide) used in this study were purchased from Sigma. Concentrated stock solutions in distilled water were stored at $-20^{\circ} \mathrm{C}$.

Cell culture. Human AML cell lines HL60 (ATTC CCL 240) and NB4 (DSM ACC 207) were cultured in RPMI 1640 (Gibco, USA) supplemented with $10 \%$ (v/v) FBS (Gibco, USA), 2 mM L-glutamine (Gibco, USA) and $50 \mu \mathrm{g} / \mathrm{ml}$ gentamycine. Cells were grown at $37^{\circ} \mathrm{C}$ in a humidified $5 \% \mathrm{CO}_{2}$ atmosphere and were routinely subcultured every 2-3 days.

For the experiments, HL60 and NB4 cells were seeded at $0.1 \times$ $106 / \mathrm{ml}$ in $25-\mathrm{cm}^{2}$ culture flasks (Costar) in culture medium and supplemented with $1 \mu \mathrm{M}$ ATRA or 1.6 nM PMA. Cells were harvested after 24, 48 and 72 hours and used for assays to evaluate cell differentiation.

\section{Cell differentiation assessment}

Cell proliferation. The total number of cells was determined by manual counting in Bürker chamber.

Morphology. Smears of control and ATRA/PMA-treated cells were stained with May-Grünwald solution (Merck, Germany) for 2 minutes, rinsed with distilled water and stained with Giemsa $(0.4 \%$ solution in methanol; Sigma, Germany) for 10 minutes. Slides were rinsed thoroughly with distilled water and air dried. Cell morphology was studied by light microscopy under immersion.

Nitroblue tetrazolium (NBT) reduction assay. In order to evaluate the differentiation induction in NB4 and HL60 cells, NBT assay, a reliable marker for differentiation of myeloid leukemia cells, was carried out on ATRA- and PMA-treated cells. Cells $\left(0.5 \times 10^{6}\right)$ were harvested at the indicated times, resuspended in $2 \mathrm{ml}$ RPMI 1640 medium containing $0.1 \%$ nitroblue tetrazolium salt (NBT; Sigma) and $100 \mathrm{ng} / \mathrm{ml}$ PMA, and incubated for 15 minutes at $37^{\circ} \mathrm{C}$ in the dark. The percentage of cells containing reduced dark blue formazan deposits was determined in duplicate, under light microscope, by examining 200 cells.

Expression of CD11b and CD14 myeloid differentiation antigens. CD11b characterizes both granulocytic and monocytic differentiation; CD14 is specific to monocytic differentiation. To measure their expression, cells were suspended in culture medium at $0.5 \times 10^{6} / 0.5 \mathrm{ml}$ and plated onto slides coated with $0.1 \%$ polyL-lysine (Sigma, USA). Cells were allowed to attach for $1.5 \mathrm{~h}$ at $37^{\circ} \mathrm{C}$ in humidified atmosphere with $5 \% \mathrm{CO}_{2}$, washed once with PBS and fixed with cold $\left(-20^{\circ} \mathrm{C}\right)$ methanol:acetone (1:1) for $10 \mathrm{~min}-$ utes at $4^{\circ} \mathrm{C}$. Following triple rinse with PBS, cells were incubated at room temperature for 30 minutes in $100 \mu \mathrm{l}$ of primary antibody dilutor (PAD) comprising $10 \%$ normal goat serum, $0.1 \%$ bovine serum albumin, $0.05 \%$ thimerosal and $0.01 \% \mathrm{NaN}_{3}$ (all from Sigma). The primary mouse monoclonal antibodies: anti-CD11b (Novocastra Ltd., Newcastle upon Tyne, UK, NCL-CD11b; diluted 1:100) and anti-CD14 (Novocastra Ltd., Newcastle upon Tyne, UK, NCL-
CD14-223; diluted 1:100) were added to the cells (after ATRA and PMA incubations and after PMA incubation, respectively) and incubated overnight at room temperature. The next day, the cells were washed once with PBS, and incubated with the secondary antibody, a Cy3-coniugated goat anti-mouse IgG (Jackson IR, West Grove, PA, USA, 115-165-146; diluted 1:400) for 60 minutes in the dark. Cells were rinsed with PBS again and slides were mounted in glycerin/PBS (2:1). Negative control was performed by replacing the primary or secondary antibodies with PAD.

Slides were examined in the fluorescence microscope (Olympus BX100) equipped with U-MNG filter set. For each set of conditions, duplicate experiments were performed, and at least 100 cells per slide were counted to determine the percentage of immunopositive cells.

Drug treatment of cell lines after differentiation. Cells incubated with ATRA or PMA were washed and treated with chemotherapeutic drugs: cytosine arabinoside $(48 \mu \mathrm{M})$, daunorubicin $(0.16$ $\mu \mathrm{M})$, mitoxantrone $(0.8 \mu \mathrm{M})$ or etoposide $(16 \mu \mathrm{M})$ for 24 hours. 72 -h cultures with PMA were excluded from this part of experiment because of decreased cell number and increased apoptosis. Drug concentrations chosen reflected the doses which resulted in a $50 \%$ decrease in cell survival (LD50). These concentrations were based on results of our previous in vitro studies (data not shown). Control cultures in drug-free medium were carried out in parallel.

Assessment of drug effect. The cell survival and cytotoxic effect was determined using Alamar Blue reduction assay. After incubation with ATRA or PMA, washed cells were resuspended at 2 $\times 10^{5} / \mathrm{ml}$ in culture medium with Alamar Blue $(0.2 \%)$ and then placed into 96 -well plates in the volume of $100 \mu \mathrm{l} /$ well. Cells were incubated at $37^{\circ} \mathrm{C}$ in humidified atmosphere with $5 \% \mathrm{CO}_{2}$ for 2 hours in the dark and then the intensity of fluorescence emitted with the reduction of Alamar Blue was measured with Microplate Fluorescence Reader FL600 (Bio-Tek Instruments, Inc., Vermont, USA) (excitation wave: $530-560 \mathrm{~nm}$, emission wave: $590 \mathrm{~nm}$ ) to evaluate fluorescence level before drug additon. Next, drugs were added to the wells. After $24 \mathrm{~h}$ cells were washed by plate centrifugation, resuspended in fresh culture medium containing $0.2 \%$ Alamar Blue and assessed again as described above. The proliferation and survival rates were calculated according to the formulas:

Cell growth index $(\%$ proliferation $)=$ Fluorescence signal intensity after incubation with drug / Fluorescence signal intensity before incubation with drug $\times 100 \%$;

Survival index $(\%$ viability $)=$ Fluorescence signal intensity after incubation with drug / Fluorescence signal intensity for untreated control x $100 \%$.

Identification and quantification of apoptotic cells with Hoechst 33342. Nuclear morphology of control and treated cells was studied by fluorescence microscopy after staining cell nuclei with Hoechst 33342 (Sigma); apoptotic cells were characterized by condensation of chromatin and/or nuclear fragmentation. The smears, prepared on glass slides, were washed twice in PBS $(\mathrm{pH}=7.4)$, fixed in formaldehyde ( $4 \%$ solution in PBS) for $15 \mathrm{~min}$ utes at room temperature and incubated with Hoechst 33342 $(5 \mu \mathrm{g} / \mathrm{ml}$ in distilled water) for 10 minutes at room temperature. They were then washed 5 times in PBS, mounted in glycerin/PBS solution (1:2) and coverslipped. Cells (at least 100 per slide) were examined under a fluorescence microscope (Olympus BX50) by using the MNU2 filter.

Statistical analysis. Data are expressed as mean \pm standard error of 5 experiments. Results were analysed using one-way analysis of variance. P-values $<0.05$ were regarded as significant. Statistical analysis was performed using Statgraphics 2.1 for Windows (Manugistic, USA). 


\section{Results}

\section{ATRA and PMA inhibit proliferation of HL60 and NB4 cell lines}

The anti-proliferative effect of ATRA and PMA was studied by measuring the total number of cells in each culture. As shown in Fig. 1, ATRA and PMA significantly ( $<<0.001$ and $p<0.005$, respectively) inhibited proliferation of both HL60 and NB4 cells after 48- and 72 hours, in comparison with untreated control. This effect was strongest in PMA-treated cells.

\section{Morphological changes}

Incubation with ATRA or PMA resulted in morphological changes of cells revealed by May-GrünwaldGiemsa staining. As shown in Fig. 2, morphological features of granulocytic differentiation, such as segmented nuclei and condensed chromatin were clearly evident in ATRA-treated HL60 and NB4 cell lines.

PMA-treated leukemia cells displayed features typical of mature monocytes and macrophages and not found in control cells: decreased nucleocytoplasmic ratio, chromatin condensation, round or oval peripherally located nucleus, irregular cytoplasmic contours and greyish cytoplasm. Cell cultures with PMA analysed after $72 \mathrm{~h}$ displayed a moderate number of apoptotic cells.

In the absence of ATRA or PMA, no sign of granulocytic or monocytic maturation was observed in either HL60 or NB4 cells.

\section{NBT assay}

The ability of cells to reduce NBT was observed $24 \mathrm{~h}$ after ATRA or PMA treatment and increased significantly after 48 and $72 \mathrm{~h}$. HL60 cells were more sensitive to PMA stimulation: the number of NBT-positive cells was significantly higher after treatment with PMA than with ATRA. Moreover, the effect of ATRA was considerably lower in these cells than in NB4 cells.

The NB4 cells showed similarly high NBT reduction after ATRA- and PMA-treatment. About $10 \%$ of untreated HL60 and NB4 cells were NBT-positive (Fig. 3).

\section{Expression of surface antigens}

About 3\% of unstimulated cells expressed CD11b and CD14 cell surface antigens. The population of CD11band CD14-positive cells increased by almost $20-40 \%$ after $24 \mathrm{~h}$ incubation with differentiating agents: ATRA or PMA. For both cell lines, the percentage of CD11b-possitive cells was the highest after ATRA treatment. The percentage of cells expressing CD14 (only after PMA stimulation) was higher in HL60 cells than in NB4 cells; the differences were statistically significant after 48- and $72 \mathrm{~h}(\mathrm{p}<0.05)$ (Fig. 4).
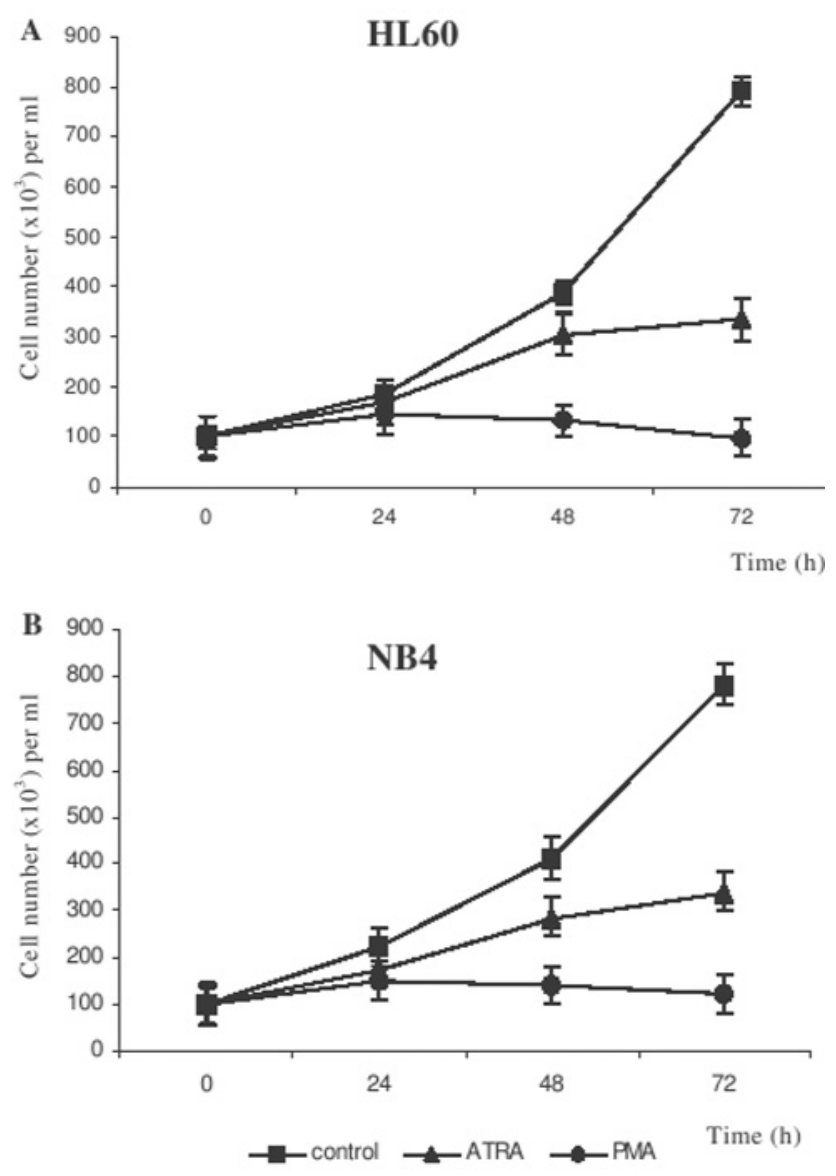

Fig. 1. Growth inhibition of (A) HL60 and (B) NB4 cell lines after ATRA $\left(10^{-6} \mathrm{M}\right)$ or PMA $(1.6 \mathrm{nM})$ treatment. Data are means $\pm \mathrm{SD}$ of 5 independent experiments.

\section{Drug sensitivity of cells after differentiation}

After ATRA or PMA treatment, both cell lines showed similar behavior in response to drugs.

ATRA-induced differentiation. Preincubation with ATRA increased sensitivity of cells towards Ara-C or mitoxantrone compared with unstimulated cells, as reflected by decreased proliferation and survival rates (cytostatic and cytotoxic effects) $(\mathrm{p}<0.05)$. An opposite effect was observed for etoposide $(p<0.05)$. Pretreatment with ATRA did not change the cell sensitivity to daunorubicin. These results were confirmed by apoptosis rate: preincubation with ATRA significantly increased apoptosis in Ara-C treated cells and reduced apoptosis induced by etoposide. ATRA however, statistically decreased apoptosis rate after daunorubicin treatment and did not significantly influence mitoxantrone-induced apoptosis. Both HL60 and NB4 cells stimulated to differentiation by ATRA showed similar sensitivity to all drugs tested. The observed effects were not dependent on the duration of ATRA pretreatment (Fig. 5 A, C, E). 


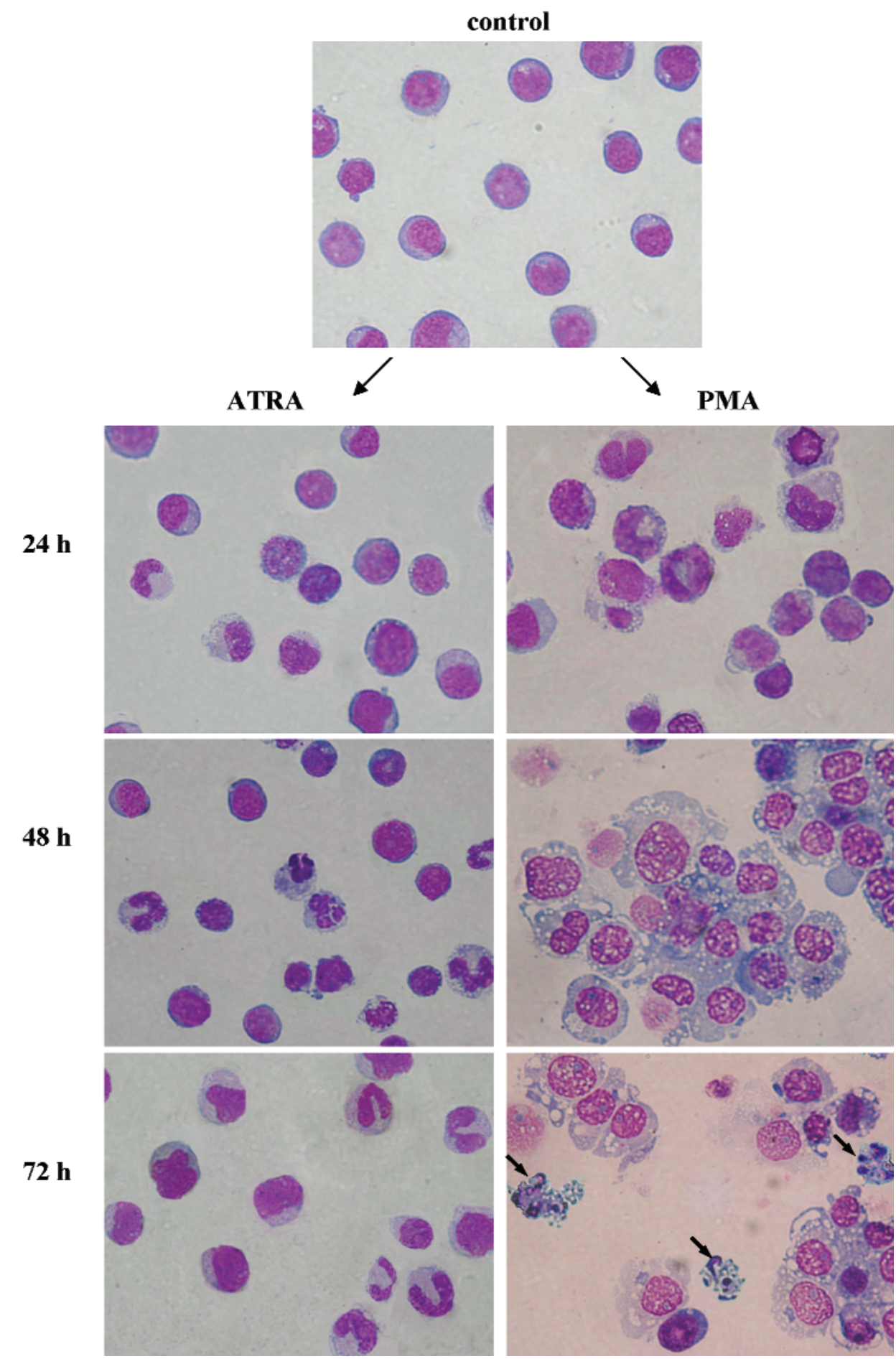

Fig. 2. May-Grünwald-Giemsa stained cytosmears of HL60 cells: untreated (control) and treated with ATRA or PMA. Arrows indicate apoptotic cells (magnification $\mathrm{x} 400)$.
PMA-induced differentiation. The differentiation after PMA treatment resulted in the decreased sensitivity of both HL60 and NB4 cells to all drugs tested. The proliferation and survival rates were higher and the apoptosis rate was markedly lower in PMA- prestimulated cells than in unstimulated control (Fig. $5 \mathrm{~B}, \mathrm{D}$, F). This effect was similar for all drugs and did not depend on the duration of PMA pretreatment.

\section{Discussion}

Under experimental conditions of this study, ATRA and PMA induced differentiation of HL60 and NB4 cells, manifested by inhibition of cell proliferation, morphological changes, capacity of oxidative burst production and expression of CD11b and CD14 differentiation markers. All tested parameters indicating cell differentiation were increased after ATRA- or PMA- 
$\mathbf{A}$

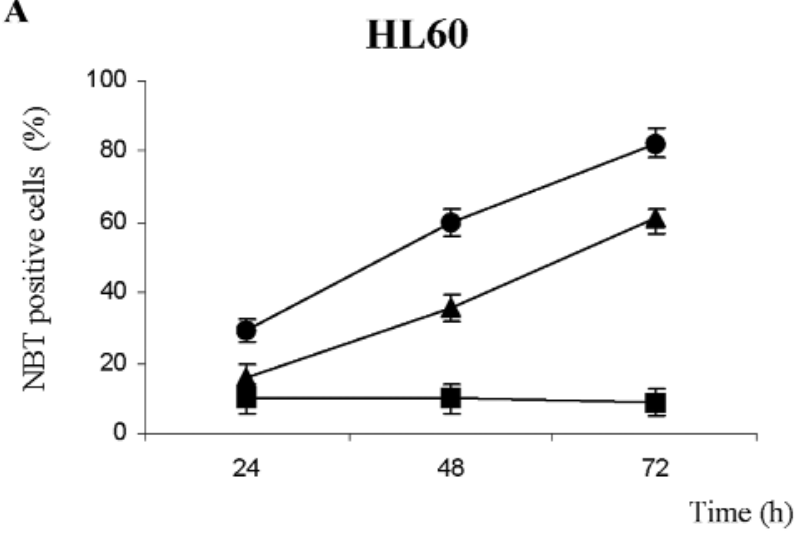

B

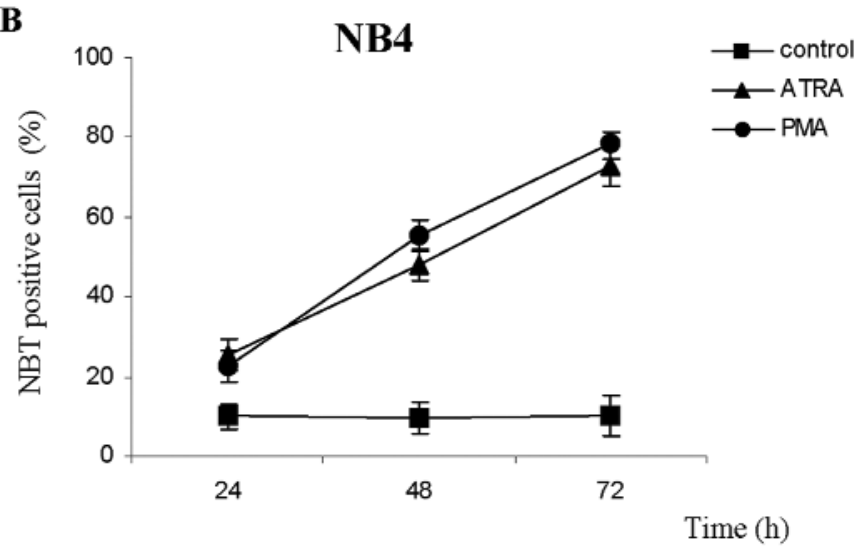

Fig. 3. Induction of NBT-reducing ability of (A) HL60 and (B) NB4 cells. The percentage of cells (NBT-positive) containing reduced dark blue formazan deposits was determined in duplicate, under light microscope, by examining 200 cells. Data are means \pm SD of 5 independent experiments.

$\mathbf{A}$
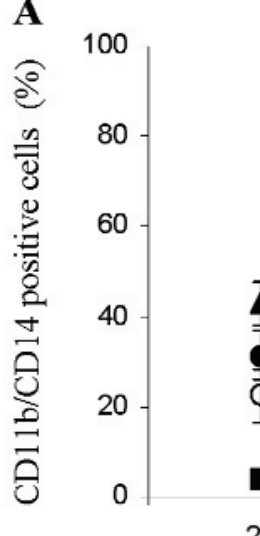

HL60

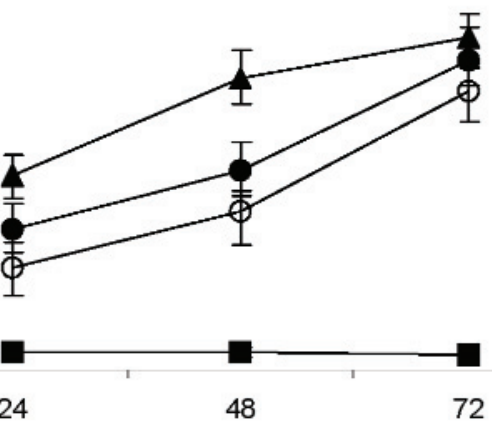

72 Time $(\mathrm{h})$

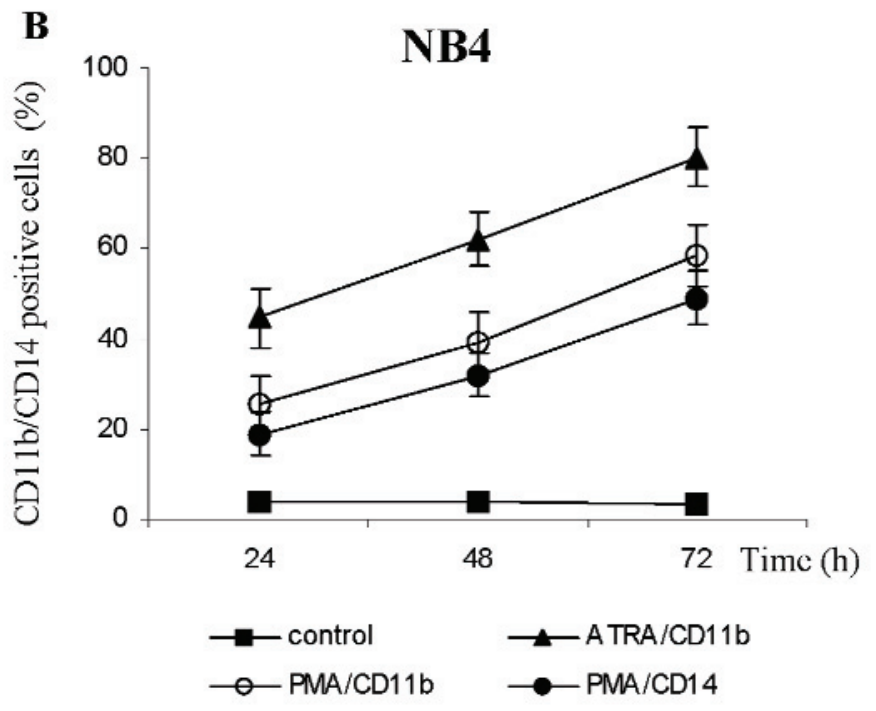

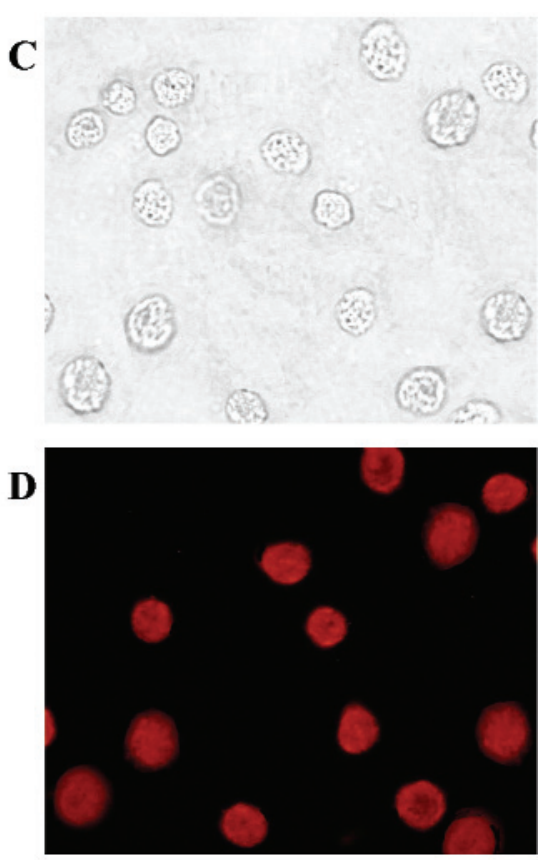

Fig. 4. Effect of ATRA or PMA on the expression of the differentiation markers: CD11b and CD14 in HL60 (A) and NB4 (B) cells. Duplicate experiments were performed, and at least 100 cells per slide were counted to determine the percentage of cells showing red fluorescence. Data are means \pm SD of 5 independent measurements. Light (C) and fluorescence (D) microscopy images of the same field of ATRA-treated HL60 cells $(72 \mathrm{~h})($ magnification $\times 200)$. treatment, however, their dynamics was not identical. According to NBT reduction assay results, HL60 cells were much more capable to produce oxidative burst after stimulation with PMA, whereas NB4 cells showed similar response after ATRA and PMA.
CD11b and CD14 antigen expression was stronger after ATRA treatment, while the cell proliferation was strongly inhibited after PMA treatment. These diverse effects suggest that different signalling pathways may be involved in the regulation of the differentiation pro- 

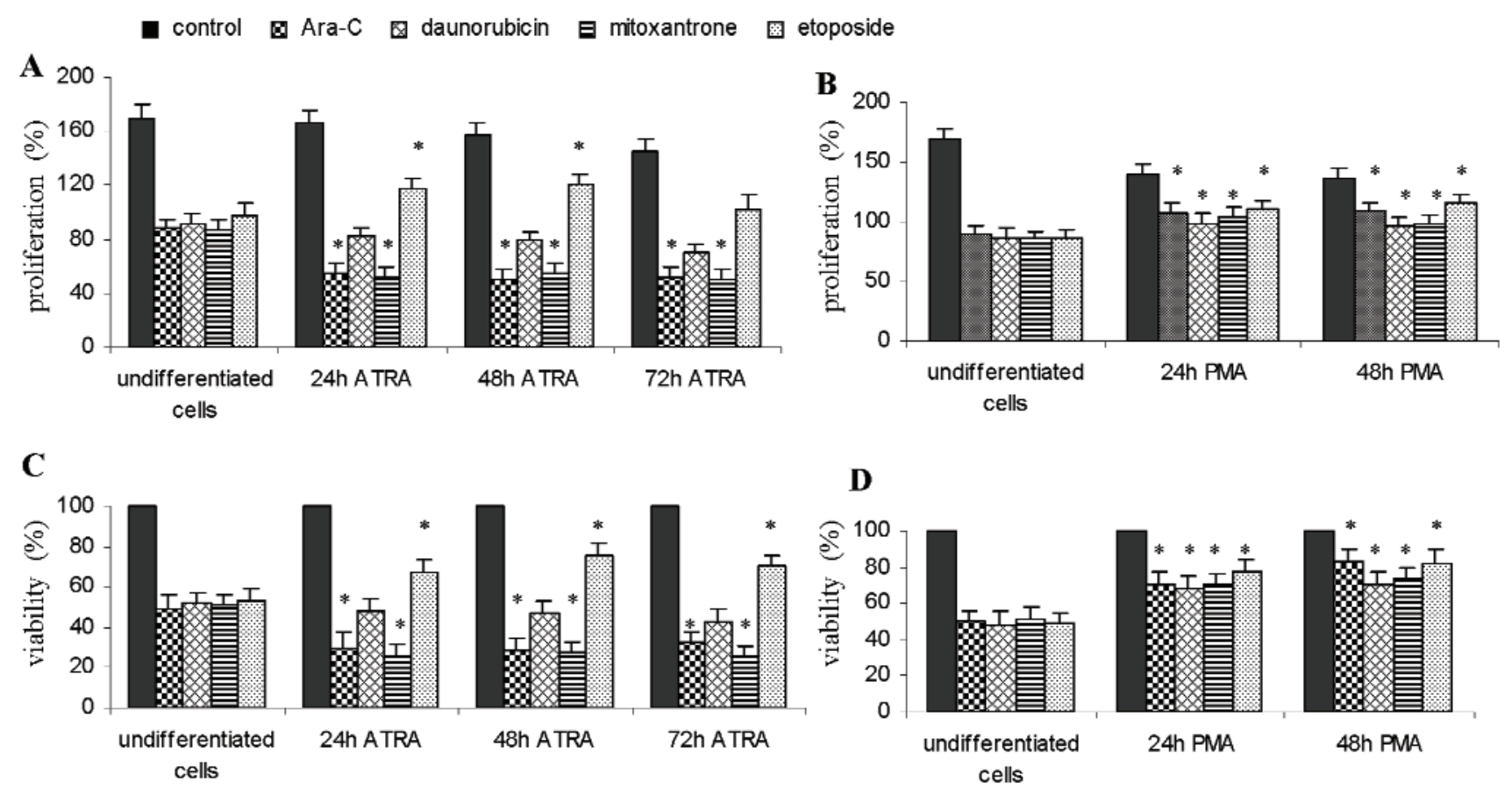

\title{
D
}
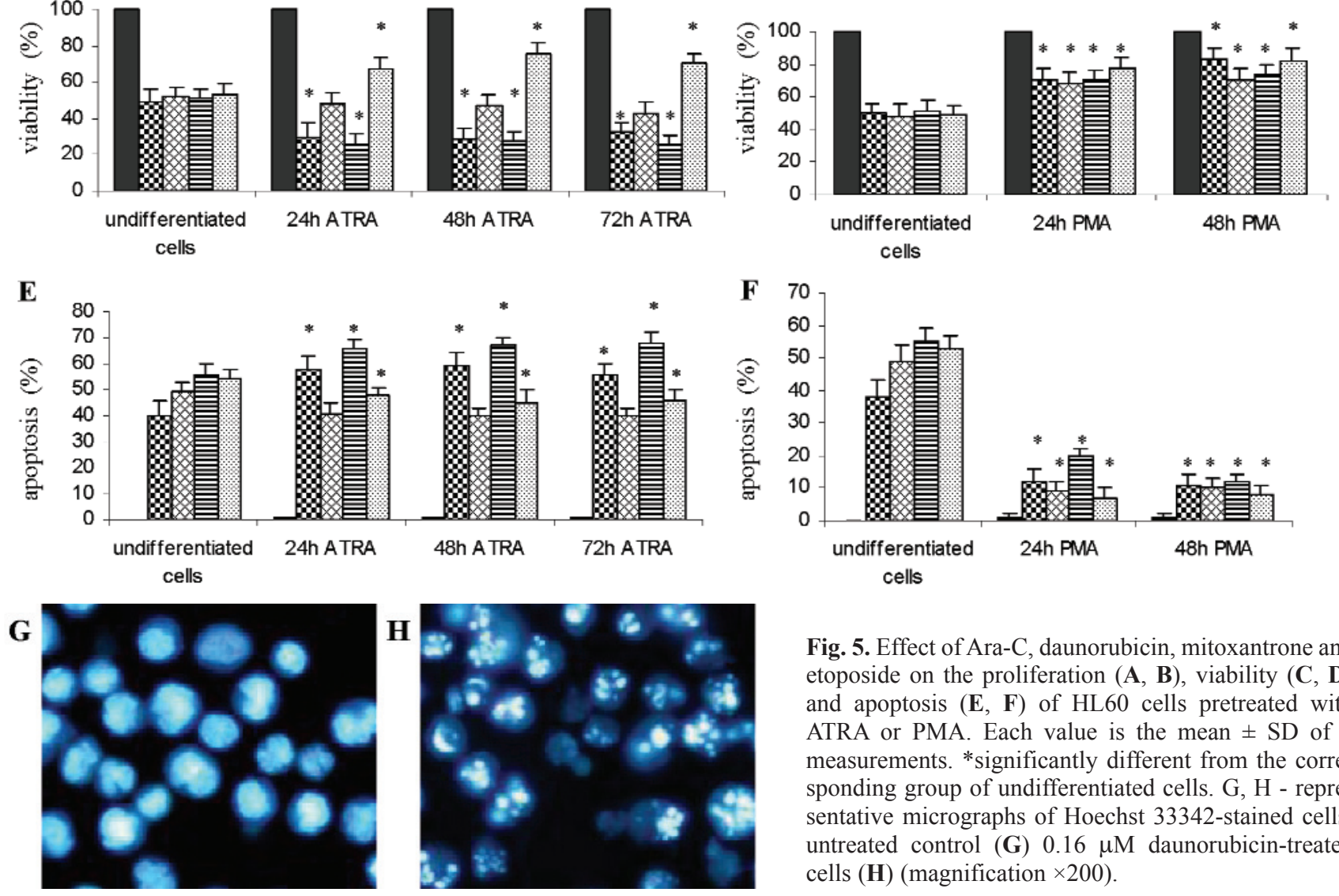

\begin{abstract}
Fig. 5. Effect of Ara-C, daunorubicin, mitoxantrone and etoposide on the proliferation $(\mathbf{A}, \mathbf{B})$, viability $(\mathbf{C}, \mathbf{D})$ and apoptosis (E, F) of HL60 cells pretreated with ATRA or PMA. Each value is the mean \pm SD of 5 measurements. *significantly different from the corresponding group of undifferentiated cells. G, H - representative micrographs of Hoechst 33342-stained cells: untreated control (G) $0.16 \mu \mathrm{M}$ daunorubicin-treated cells $(\mathbf{H})$ (magnification $\times 200$ ).
\end{abstract}

gram. Moreover, it has been reported that the differentiation process in leukemia cells may be different than in normal hematopoietic cells [17]. HL60 cell line has been found to differentiate in response to ATRA into neutrophils which are not identical to normal mature cells and do not always express the same antigens as mature neutrophils. For example, ATRA does not induce on HL60 cells the expression of CD16, CD66 and CD88 antigens, which are normally expressed on granulocytes [18]. In addition, it has been noticed that neither fresh APL cells nor promyelocytic cell lines express secondary granules after incubation with ATRA [19].

There is a growing number of publications documenting that differentiation process of leukemia cells may modulate their sensitivity to chemotherapeutic drugs [20-24]. In our in vitro model we have shown that ATRA increases sensitivity of HL60 and NB4 cells to Ara-C and mitoxantrone. This is in agreement with some data in the literature: previous studies have shown that ATRA modulates the expression of proand antiapoptotic proteins. The reduction of intercellular level of antiapoptotic Bcl-2 protein was found during stimulation of differentiation in AML cell lines as well as in normal hematopoietic progenitors $[11,25,26]$. Moreover, other authors demonstrated that NB4 cells incubated with ATRA overexpressed TRAIL protein, a mediator of extrinsic apoptosis pathway [27]. On the other hand, some standard chemothera- 
peutic drugs, such as Ara-C, when used at low concentrations can also induce differentiation of leukemia cells $[28,29]$. Hence, the decreased cell survival observed in our experiments after preicubation with ATRA and subsequent treatment with anticancer agents: Ara-C and mitoxantrone might be a summative effect of two differentiation-inducing stimuli, ultimately leading to apoptosis.

In contrast, the present study demonstrated that HL60 and NB4 cells stimulated to differentiation along the monocyte/macrophage pathway decreased their sensitivity to all drugs tested. This is in accordance with the results presenting by Sordet et al. [24] who have shown that PMA inhibits etoposide-induced apoptosis of HL60 and U937 cell lines, suggesting that the failure of PMA-stimulated cells to enter apoptosis might be the effect of protein kinase $\mathrm{C}$ (PKC) activation. However, this effect can also be independent of PKC activity: it has been shown that PMA inhibits sphingomyelinase activity and decreases ceramide production preventing apoptosis [30] and that PMAtreated cells are resistant to Fas-L-induced apoptotic cell death [31]. Moreover, other studies have shown that phorbol esters increase the level of antiapoptotic proteins (Bcl-2, Bcl-XL, Mcl-1), especially in adherent cells stimulated to differentiate [32-34].

It is interesting to note that differentiation inducers may have an effect on cell cycle. It is well established that the sensitivity of malignant cells to chemotherapeutic drugs is highest when cells are in $S-$ and $\mathrm{G}_{2} / \mathrm{M}$ phase. Recent studies have shown that ATRA stimulation of leukemia cells in vitro results in decreased fraction of cells in the $\mathrm{S}$ and $\mathrm{G}_{2} / \mathrm{M}$ phase $[22,35]$. We have demonstrated strongly decreased sensitivity to etoposide induced by both ATRA and PMA. It might be due to inhibition of topoisomerase II activity by etoposide - an effect which is the strongest in S phase [36]. Another possibility is increased efficiency of DNA repair processes mediated by $\mathrm{p} 21$ protein in cells stimulated to differentiation. The p21 protein is an inhibitor of cell cycle regulated by p53. HL60 and NB4 cell lines lack functional $\mathrm{p} 53$, hence induction of $\mathrm{p} 21$ protein during differentiation may occur independently of $\mathrm{p} 53$, since high p21 expression was observed in HL60 cells after induction of differentiation [22,37].

In our studies, the sensitivity of ATRA-pretreated cells towards daunorubicin did not change and was decreased in cells preincubated with PMA. As reported previously, decreased level of Bcl-2 protein in ATRAdiferentiated HL60 and NB4 cells might be compensated by upregulation of other antiapoptotic proteins of Bcl2 family, e.g. Mcl-1 and Bfl-1/A1 [25,38-40]. Moreover, it has been shown that doxorubicin (anthracycline drug similar to daunorubicin) decreased apoptosis in ATRAtreated APL cells and Bfl-1/A-1 may be responsible, at least in part, for this effect [25]. Interestingly, daunoru- bicin is thought to trigger both apoptotic and survival pathways in the treated cells $[41,42]$. Anticancer agents and differentiation inducers may then have different or complementary effects on survival of leukemia cells.

The duration of treatment with ATRA or PMA did not affect the level of cell sensitivity, suggesting that just the initiation of differentiation process may be important for the reaction of cells to chemotherapeutic drugs. It has been reported that shorter treatment of HL60 and NB4 cells with ATRA (for 3-24 h) resulted in the upregulation or downregulation of many genes involved in the initiation of differentiation. For example, genes participating in signal transduction pathways (retinoic acid receptor $\beta$ ) were upregulated after $8 \mathrm{~h}[43,44]$.

We have to take into consideration, however, that not only differentiation process but also the way of its induction might be important for chemosensitivity of cells. In our studies, we have observed different effects of drugs upon treatments inducing granulocytic pathway (ATRA) and monocytic pathway (PMA).

In conclusion, we have shown that ATRA- and PMA-mediated differentiation of human myeloid leukemia cell lines results in the changes of their drug sensitivity. Our data may provide a contribution to a strategy aimed at a rational combination of differentiating agents and conventional anticancer drugs.

Acknowledgements: The authors would like to thank Dr. Mariusz Gajda for his expert advice on immunohistochemistry. This study was supported by grant 501/P/171/L from the Jagiellonian University Medical College.

\section{References}

[ 1] Idres N, Benoit G, Flexor MA, Lannote M, Chabot GG. Granulocytic differentiation of human NB4 promyelocytic leukemia cells induced by all-trans retinoic acid metabolites. Cancer Res. 2001;15:700-705.

[2] Kambhampati S, Verma A, Li Y, Parmar S, Sassano A, Platanias LC. Signalling pathways activated by all-trans retinoic acid in acute promyelocytic leukemia cells. Leuk Lymph. 2004;45:2175-85.

[3] Zhang JW, Wang JY, Chen SJ, Chen Z. Mechanisms of alltrans retinoic acid-induced differentiation of acute promyelocytic leukemia cells. J Biosci. 2000;25:275-284.

[4] Gate L, Lunk A, Tew K. Resistance to phorbol 12-myristate 13 -acetate-induced cell growth arrest in an HL60 cell line chronically exposed to a glutathione $S$-transferase $\pi$ inhibitor. Biochem Pharmacol. 2003;65:1611-1622.

[ 5] Yang M, Chen T, Han C, Li N, Wan T, Cao X. Rab7b, a novel lysosome-associated small GTPase, is involved in monocytic differentiation of human acute promyelocytic leukemia cells. Biochem Biophys Res Commun. 2004;318:792-799.

[6] Collins SJ. The role of retinoids and retinoic acid receptors in normal hematopoiesis. Leukemia. 2002;16:1896-1905.

[ 7] Oren T, Sher JA, Evans T. Hematopoiesis and retinoids. Leuk Lymph. 2003;44:1881-1891.

[8] Zile MH. Function of vitamin A in vertebrate embryonic development. J Nutr. 2001;131:705-708.

[9] Gutcher I, Webb PR, Anderson NG. The isoform-specific regulation of apoptosis by protein kinase C. Cell Mol Life Sci. 2003;60:1061-1070. 
[10] Nakashima S. Protein kinase $\mathrm{C} \alpha(\mathrm{PKC} \alpha)$ : regulation and biological function. J Biochem. 2002;132:669-675.

[11] Bolanos-Meade J, Karp JE, Guo C, Adoo CB, Rapoport AP, Tidwell ML et al. Timed sequential therapy of acute myelogenous leukaemia in adults: a phase II study of retinoids in combination with the sequential administration of cytosine arabinoside, idarubicin and etoposide. Leuk Res. 2003;27: 313-321.

[12] Degos L, Wang ZY. All-trans retinoic acid in acute promyelocytic leukemia. Oncogene. 2001;29:7140-7145.

[13] Fenaux P, Chomienne C, Degos L. All-trans retinoic acid and chemotherapy in the treatment of acute promyelocytic leukemia. Semin Hematol. 2001;38:13-25.

[14] Vitoux D, Nasr R, de The H. Acute promyelocytic leukemia: new issues on pathogenesis and treatment response. Int $J$ Biochem Cell Biol. 2007;39:1063-70.

[15] Zhou GB, Chen SJ, Chen Z. Grant S. Acute promyelocytic leukemia: a model of molecular target based therapy. Hematology. 2005;10:270-280.

[16] Hu ZB, Minden MD, McCulloch EA. Phosphorylation of BCL-2 after exposure of human leukemic cells to retinoic acid. Blood. 1998:5:1768-1775.

[17] Riccioni R, Saulle E, Militi S, Sposi NM, Gualtiero M, Mauro $\mathrm{N}$ et al. $\mathrm{C}$-fms expression correlates with monocytic differentiation in PML-RAR $\alpha^{+}$acute promyelocytic leukemia. Leukemia. 2003;17:98-113.

[18] Trayner ID, Bustorff T, Etches AE, Mufi GJ, Foss Y, Farzaneh F. Changes in antigen expression on differentiating HL60 cells treated with dimethylsulphoxide, all-trans retinoic acid, $\alpha$-1,25-dihydroxyvitamin $\mathrm{D}_{3}$ or 12-O-tetradecanoyl phorbol13-acetate. Leuk Res. 1998;22:537-547.

[19] Miyauchi J, Ohyashiki K, Inatomi Y, Toyama K. Neutrophil secondary-granule deficiency as a hallmark of all-trans retinoic acid-induced differentiation of acute promyelocytic leukemia cells. Blood. 1997;15:803-813.

[20] Allouche M, Charrad RS, Bettaieb A, Greenland C, Grignon C, Smadja-Joffe F. Ligation of the CD44 adhesion molecule inhibits drug-induced apoptosis in human myeloid leukemia cells. Blood. 2000;96:1187-1190.

[21] Gianni M, Kalac Y, Ponzanelli I, Rambaldi A, Terao M, Garattini E. Tyrosine kinase inhibitor STI571 potentiates the pharmacologic activity of retinoic acid promyelocytic leukemia cells: effects on the degradation of RAR $\alpha$ and PML-RAR $\alpha$. Blood. 2001;97:3234-3242.

[22] Ketley NJ, Allen PD, Kelsey SM, Newland AC. Modulation of idarubicin-induced apoptosis in human acute myeloid leukemia blasts by all-trans retinoic acid, $1,25(\mathrm{OH})_{2}$ vitamin $\mathrm{D}_{3}$, and granulocyte-macrophage colony-stimulating factor. Blood. 1997;90:4578-4587.

[23] Solary E. Positive and negative regulation of apoptotic pathways by cytotoxic agents in haematological malignances. Leukemia. 2000;14:1833-1849.

[24] Sordet O, Rebe C, Leroy I, Bruey JM, Garrido C, Miguet C et al. Mitochondria-targeting drugs arsenic trioxide and lonidamine bypass the resistance of TPA-differentiated leukemic cells to apoptosis. Blood. 2001;12:3931-3939.

[25] Xia L, Wurmbach E, Jing Y. Upregulation of Bfl-1/A1 in leukemia cells undergoing differentiation by all-trans retinoic acid treatment attenuates chemotherapeutic agent-induced apoptosis. Leukemia. 2006;20:1009-1016.

[26] Otake Y, Sengupta TK, Bandyopadhyay S, Spicer EK, Fernandez DJ. Retinoid induces apoptosis in HL-60 cells is associated with nucleolin down-regulation and destabilization of Bcl-2 mRNA. Mol Pharmacol. 2005;67:319-326.

[27] Altucci L, Rossin A, Raffelsberger W, Reitmair A, Chomienne C, Gronemeyer H. Retinoic acid-induced apoptosis in leukemia cells is mediated by paracrine action of tumor-selective death ligand TRAIL. Nat Med. 2001;6:680-686.
[28] Bruserud O, Gjertsen BT. New strategies for the treatment of acute myelogenous leukemia: differentiation induction - present use and future possibilities. Stem Cells. 2000;18:157-165.

[29] Takagaki K, Katsuma S, Kaminishi Y, Horio T, Tanaka T, Ohgi T et al. Role of Chk1 and Chk2 in Ara-C-induced differentiation of human leukemia K562 cells. Genes Cells. 2005;10:97-106.

[30] Johns LD, Sarr T, Ranges GE. Inhibition of ceramide pathway does not affect ability of TNF-alpha to activate nuclear factorkappa B. J Immunol. 1994;15:5877-5882.

[31] Micheau O, Solary E, Hammann A, Dimanche-Boitrel MT. Fas-ligand independent, FADD-mediated activation of the Fas death pathway by anticancer drugs. J Biol Chem. 1999; 274:7987-7992.

[32] Meinhardt G, Roth J, Hass R. Activation of protein kinase C relays distinct signaling pathways in the same cell type: differentiation and caspase-mediated apoptosis. Cell Death Differ. 2000;7:795-803.

[33] Kluck RM, Bossy-Wetzel E, Green DR, Newmeyer DD. The release of cytochrome $\mathrm{c}$ from mitochondria: a primary site for Bcl-2 regulation of apoptosis. Science. 1997;275:1132-1136.

[34] Sordet O, Bettaieb A, Bruey JM, Eymin B, Droin N, Ivarsson $\mathrm{M}$ et al. Selective inhibition of apoptosis by TPA-induced differentiation of U937 leukemic cells. Cell Death Differ. 1999;6:351-361.

[35] Wang J, Barsky LW, Shum CH, Jong A, Weinberg KI, Collins SJ et al. Retinoid-induced G1 arrest and differentiation activation are associated with a switch to cyclin-dependent kinase-activating kinase hypophosphorylation of retinoic acid receptor. J Biol Chem. 2002;277:43369-43376.

[36] Gieseler F, Bauer E, Nuessler V, Clark M, Valsamas S. Molecular effects of topoisomerase II inhibitors in AML cell lines: correlation of apoptosis with topoisomerase II activity but not with DNA damage. Leukemia. 1999;13:1859-1863.

[37] Clark CS, Konyer JE, Meckling KA. 1 $\alpha, 25$-dihydroxyvitamin $\mathrm{D}_{3}$ and bryostatin-1 synergize to induce monocytic differentiation of NB4 acute promyelocytic leukemia cells by modulating cell cycle progression. Exp Cell Res. 2004;294: 301-311.

[38] Jing Y, Wang L, Xia L, Chen GQ, Chen Z, Miller WH et al. Combined effect of all-trans retinoic acid and arsenic trioxide in acute promyelocytic leukemia cells in vitro and in vivo. Blood. 2001;97:264-269.

[39] Yin W, Raffelsberger W, Gronemeyer H. Retinoic acid determines life span of leukemic cells by inducing antagonistic apoptosis-regulatory programs. Int $J$ Biochem Cell Biol. 2005;37:1696-1708

[40] Konopleva M, Zhao S, Hu W, Jiang S, Snell V, Weidner D et al. The anti-apoptotic genes $\mathrm{Bcl}-\mathrm{X}(\mathrm{L})$ and $\mathrm{Bcl}-2$ are over-expressed and contribute to chemoresistance of non-proliferating leukaemic CD34+ cells. Br J Haematol. 2002;118:521-534.

[41] Come MG, Skladanowski A, Larsen AK, Laurent G. Dual mechanism of daunorubicin-induced cell death in both sensitive and MDR-resistant HL60 cells. Br J Cancer. 1999;79: 1090-1097.

[42] Laurent G, Jaffrezou JP. Signaling pathways activated by daunorubicin. Blood. 2001;98:913-924.

[43] Bjorling-Poulsen M, Issinger OG. cDNA array analysis of alterations in gene expression in the promyelocytic leukemia cell line, HL-60, after apoptosis induction with etoposide. Apoptosis. 2003;8:377-388.

[44] Lee KH, Chang MY, Ahn JI, Yu DH, Jung SS, Choi JH et al. Differential gene expression in retinoic acid-induced differentiation of acute promyelocytic leukemia cells, NB4 and HL-60 cells. Biochem Biophys Res Commun. 2002;296:1125-1133.

Submitted: 23 January, 2008

Accepted after reviews: 16 May, 2008

CPolish Histochemical et Cytochemical Society

Folia Histochem Cytobiol. 2008:46(3): 330 (323-330)

doi: $10.2478 / \mathrm{v} 10042-008-0080-\mathrm{x}$ 